\title{
Tirando frutos de uma vinha estéril: acordos e adaptações do projeto jesuítico no Brasil (1580-1620)*
}

Maria Regina Celestino**

Charlotte Castelnau-L'Estoile, Les Ouvriers D'Une Vigne Stérile. Les jésuites el la conversion des Indiens au Brésil 1580-1620, Lisbonne-Paris, Fundação Calouste Gulbenkian, 2000. ${ }^{1}$

Nas últimas décadas, índios e jesuítas têm ganhado espaço em pesquisas interdisciplinares que procuram repensar suas relações de contato. Nestes estudos, os índios, em geral, surgem como principal foco de interesse dos pesquisadores que procuram refletir sobre as mudanças por eles vivenciadas, considerando-os também agentes destas mudanças. $\mathrm{O}$ aspecto religioso costuma ser priorizado e os jesuítas aparecem como

${ }^{*}$ Resenha recebida em abril de 2005 e aprovada para publicação em maio de 2005.

** Professora do Departamento de História da Universidade Federal Fluminense. E-mail: reginacelestino@uol.com.br.

${ }^{1} \mathrm{O}$ livro foi publicado no Brasil em 2006 pela EDUSC (Editora da Universidade do Sagrado Coração) com o título: Operários de uma vinha estéril - os jesuítas e a conversão dos índios no Brasil-1580-1620. 
importantes atores com os quais interagem os índios nestes processos de metamorfose. Cristina Pompa, Eduardo Viveiros de Castro, John Monteiro, Manuela Carneiro da Cunha e Ronaldo Vainfas são alguns exemplos de historiadores e antropólogos que, dos anos 1990 para cá, têm abordado o tema nesta perspectiva. Nestes trabalhos, bem como em outros que os antecederam, em perspectiva diversa, os inacianos desempenham papel essencial como agentes transformadores das culturas indígenas e, sobretudo, como produtores de fontes primárias fundamentais para o tema, porém não constituem o foco central de suas abordagens. Mais recentemente, José Eisemberg inovou ao abordar as missões, privilegiando o pensamento político da ordem jesuítica e refletindo sobre suas mudanças a partir da prática missionária.

É este também o principal enfoque do livro de Charlotte Castelnau-L'Estoile que, numa linha interdisciplinar, apresenta abordagem original e relevante, ao focalizar o projeto missionário em si e o impacto das relações de contato e da prática da evangelização sobre os próprios missionários e sobre o projeto da Companhia de Jesus, enfatizando suas reformulações em face das dificuldades encontradas na conversão dos índios na virada do século XVI para o
XVII. Trata-se de análise sólida e brilhante, muitíssimo bem fundamentada na vasta e variada documentação jesuítica desse período, através da qual a autora traça o perfil da Companhia de Jesus em Roma, da Província no Brasil, dos diferentes missionários que ocupavam as mais variadas posições na Província, analisando as complexas relações estabelecidas entre eles na prática missionária, sem descuidar da contextualização histórica, pano de fundo essencial em toda a sua obra. O grande mérito da autora está em evidenciar as necessárias adaptações do projeto missionário às condições locais, interessando-se, como ela própria afirma, em realizar uma análise precisa de uma estratégia provincial num momento dado. Na sofisticada análise de Charlotte, o projeto missionário se constrói por meio da dinâmica das relações entre Centro e Província que, longe de ser vista como via de mão única, desdobra-se em toda a sua complexidade, revelando o intenso jogo de discordâncias e negociações, através do qual, num processo ininterrupto, as partes se vão entendendo, as adaptações vão sendo feitas e as normas se vão estabelecendo e continuamente se modificando.

O foco da análise é o projeto missionário e suas práticas na Província, e o tempo é o da consolida- 
ção da ordem e da regulamentação do projeto missionário no Brasil - 15801620. O marco inicial é a Visita de Cristóvão de Gouveia, cuja missão, nas palavras de Aquaviva, deve ser "a consolação dos nossos que trabalham naquela vinha tão estéril, laboriosa e perigosa". Esta forma de se referir à missão no Brasil expressa as dificuldades enfrentadas na prática missionária, e o envio da Visita é a iniciativa do Centro para a reformulação da prática missionária de forma a enfrentar as dificuldades. O marco final é a festa de canonização dos padres Ignácio de Loyola e Francisco Xavier, que sinaliza a idéia de triunfo da missão, apesar de todas as dificuldades. Duas festas com funções semelhantes e em tempos diversos abrem e fecham a obra de Charlotte: a festa descrita por Cardim em 1585 e a canonização de 1622 têm, ambas, a função de construir uma imagem positiva da Província em tempos difíceis. Entre uma e outra, muita tinta se gastou na produção de inúmeros e variados documentos administrativos e literários que, ao invés de serem vistos como contraditórios, são confrontados e lidos pela autora de forma complementar, revelando a coerência e a complexidade do projeto missionário.

A especificidade da conversão dos índios do Brasil fez com que a missão, itinerante por definição, se tornasse fixa, através da política de aldeamentos, o que constitui um dos principais paradoxos entre o projeto missionário da Companhia e sua prática na Província do Brasil. Esta questão - a adaptação das regras de Roma à realidade da Província - é o fio condutor desta obra que, além de analisar a inserção dos jesuítas na sociedade colonial, não se limita a descrever as práticas catequéticas, mas intenta decifrar seu significado para a ordem e para os missionários, procurando entender o sentido de buscar sua salvação por meio da salvação do outro, o que a inscreve no campo da antropologia religiosa e da história colonial. Argumentação lúcida e interpretação acurada de variadas fontes revelam que o projeto jesuítico tinha uma preocupação maior com salvação do missionário do que com os índios.

A obra compõe-se de cinco partes. A primeira, intitulada " Uma Visita' da Província do Brasil" apresenta ao leitor, através da narrativa do Padre Fernão Cardim, acompanhante do Visitador Cristóvão Gouveia, um quadro minucioso da Província Jesuítica do Brasil, vinculada à sociedade colonial, na qual os padres se inseriam, aproximando-se de elites e autoridades e desenvolvendo atividades econômicas. Estas atitudes que, 
segundo a autora, eram importantes estratégias dos jesuítas para adequarem a Província às mudanças ocorridas na sociedade colonial, geravam controvérsias no seio da Companhia. A narrativa idílica de Cardim é questionada e contrastada com a imagem de vinha estéril, que aponta para as imensas dificuldades encontradas pelo projeto missionário depois de 30 anos de experiência, quando a fase de ilusões dera lugar à de decepções. O papel fundamental da escrita missionária e as regras que a orientavam revelam-se na refinada investigação da autora. Importante demais para ser livre, a escrita obedecia a normas rígidas e cumpria um papel essencial, com o objetivo de informar os padres sobre o que se passava com outros e fortalecer a dimensão espiritual da ordem e a identidade jesuítica. Esta é traçada a partir das Constituições, cujas regras admitiam a diferença, pois a adaptabilidade era uma resposta à dispersão dos membros e a Visita vinha constatar esta diferença para normatizar a partir dela.

$\mathrm{Na}$ segunda parte, intitulada "A Negociação da Ordem Missionária", a autora discute basicamente as adequações das normas da Ordem à realidade da Província no Brasil, refletindo sobre a produção do Regulamento de 1586, resultado das negociações dos padres locais com o Visitador Gouveia, que procurava conciliar o espírito das Constituições com as necessidades da Província. Das especificidades locais surgiam vários problemas e contradições com as regras de Roma: a aldeia fixa, na qual os índios eram reunidos e separados dos europeus, se impôs por razões políticas, religiosas e econômicas, opondo-se ao ideal missionário de valorizar a peregrinação e a missão como provações espirituais importantes. Além disto, a missão do Brasil incluía-se, segundo as Constituições, na categoria daquelas "que têm mais perigos espirituais, para as quais devem ser enviados missionários com poucas letras e muitas virtudes", decorrendo daí várias divergências com o Centro, visto que os padres mais adequados para as aldeias no Brasil não eram os mais preparados, segundo as normas da Companhia. A presença de coadjutores temporais nas aldeias, por exemplo, proibida por Roma, era freqüente e necessária no Brasil, tendo sido admitida pelo Regulamento, em situações excepcionais. A Visita acabou por reiterar a necessidade de manter as aldeias tal como estavam organizadas e tornou obrigatório o aprendizado da língua indígena, gerando novas resistências e muitas negociações. Sobre a inserção dos jesuítas na política colonial, aconselhou uma posição mediana 
entre colonos e índios. Embora Roma quisesse evitar confrontos dos jesuítas com os poderes civis, tentando proibir seu envolvimento com a política indigenista, esta medida era impraticável no Brasil, onde a existência das aldeias e do próprio projeto missionário dependia de um complexo jogo de forças entre a Coroa, os missionários e os colonos.

"O Lugar dos Missionários na Província” é cuidadosamente investigado na terceira parte, onde Charlotte analisa a política de pessoal, identificando os talentos e as competências dos missionários e sua distribuição na Província a partir, principalmente, do Catálogo trienal de 1598. Reflete sobre a lógica da produção dos catálogos e a organização de suas variadas rubricas, apontando os possíveis limites e imprecisões das informações ali reveladas para, então, realizar refinado cruzamento dos diferentes dados dos vários catálogos e de outros documentos, fazendo emergir o perfil dos missionários do Brasil que, em seu texto, se limitam aos dedicados às aldeias. Eram, em geral, mais velhos, conhecedores da língua indígena e com uma formação intelectual fraca, tendo dedicado quase toda a vida à conversão. Em contrapartida e em contradição com o princípio da Companhia, segundo o qual a missão era o ideal mais importante na Província, estes padres das aldeias não ocupavam cargos de destaque no governo, nem atividades espirituais de prestígio, tendo sido Anchieta uma exceção. Esta contradição gerava inúmeras divergências entre o Centro e a Província, caracterizada pelos dualismos entre os intelectuais do Colégio e as línguas das aldeias, entre teologia e língua brasileira, entre vida fácil e de prestígio nos colégios e árdua e pouco valorizada na aldeia. A especificidade da política de pessoal na Província gerou muitas polêmicas e conduziu a autora à instigante indagação discutida na parte seguinte: Roma, centro da Companhia, e Brasil, Província periférica longínqua, compartilhariam das mesmas concepções de missão?

É esta a principal questão da quarta parte do livro, intitulada "A administração da Conversão: exigências do centro e estratégias locais" - na qual Charlotte se volta para os diálogos administrativos entre a Província e Roma, enfocando principalmente a conversão dos índios a partir da correspondência dos superiores e das atas das Congregações provinciais. Reflete sobre as conexões entre Centro e Periferia e recompõe as diferentes lógicas que se entrecruzam nas questões missionárias. Charlotte retoma e complexifica as divergências internas da ordem sobre a administração temporal das aldeias e as 
disputas na colônia dos jesuítas com outros agentes sociais, considerando inclusive a legislação. Explora e cruza informações de diferentes documentos, como as atas das congregações, a rica correspondência entre Aquaviva e o Provincial Pero Rodrigues e os documentos produzidos pela Visita de Manuel de Lima à Província - 16071610, que expressam a opinião do Centro através de seus representantes, revelando, inclusive, diferenças entre eles. Manuel de Lima, o Visitador, procurava adaptar as ordens de Roma à realidade local, compondo com os superiores da Província o Regulamento, enquanto seu consultor e acompanhante Jácome Monteiro, radical representante do pensamento de Roma, aconselhava o abandono das aldeias por considerá-las a causa dos problemas da Companhia no Brasil, onde não se salvavam os índios e se perdiam os missionários. Fundamental para investigar as estratégias locais em face das investidas do Centro é o documento intitulado "Algumas advertências para a Província do Brasil" que, segundo a autora, devem ter sido escritas como documento preparatório para a Assembléia de 1609, convocada pelo Visitador. Nele, a missão aparece como questão política e estratégia essencial para a Província, cujo coração está nas aldeias. O documento explicita a importância da lógica colonial para o projeto missionário que se desenvolve dentro dela. Se Roma queria abandonar as aldeias para evitar a perdição dos missionários e manter o espírito da Companhia, os superiores da Província acreditavam que a manutenção deste "espírito" passava pelo zelo missionário e era absolutamente necessário manter as aldeias que constituíam uma das bases do poder econômico e político dos jesuítas na colônia.

"A Prática da Escrita da Missão" é a quinta parte do livro, na qual Charlotte desenvolve cuidadosa análise sobre os princípios da construção dos textos de dimensões pública e literária, destinados a grande circulação. São textos variados, escritos com o objetivo de edificar uma obra considerada pouco frutífera, e incluem cartas, cujo modelo é a ânua provincial, tratados descritivos dos povos, da fauna e da flora, exposições das viagens, discursos históricos e vidas devotas. Tratam da conversão, incluindo três temas principais: a terra, os índios e os missionários, tendo, portanto, dimensão administrativa e espiritual. A autora examina criteriosamente cada uma destas modalidades nos contextos em que foram escritas, considerando os objetivos a que se destinavam. A descrição otimista de Cardim, por exemplo, categorizada como escrita de consolação, que pro- 
curava incentivar os padres a virem ao Brasil, é comparada com a narrativa de Jácome Monteiro que, alguns anos depois, já sob a influência da escrita de Acosta, visava relatar a realidade da Província, expondo as dificuldades da missão. As escritas sobre experiências de viagem, analisadas principalmente através das concepções do Provincial Pero Rodrigues, expressas em carta de 1599, demonstram a importância dada na Província aos padres que viviam a experiência missionária nas aldeias e nas expedições do sertão. A valorização destas atividades no momento político de confronto com o Centro, quando os padres tinham intensa participação em atividades temporais na Colônia, garantidas pela Coroa e questionadas por Roma, demonstra o papel edificante, político e diplomático destas narrativas. Finalmente, Charlotte trata das hagiografias que se inauguram na Província depois da morte de Anchieta (1597) e também se revelam como importante escrita de caráter político e edificante, pois reforçam o ideal da Província frente a Roma. Tratava-se de construir uma imagem do santo missionário que reunia em sua pessoa todas as dificuldades da missão, em época de imensos desafios. É o momento, como diz a autora, em que a "imagem de vinha estéril dá lugar a de fruto colhido". Esta afirmativa é válida também para a Companhia, que está, então, fazendo canonizar seus dois santos fundadores.

Finalmente, no epílogo, Charlotte trata da festa de canonização, na qual se misturam as manifestações religiosas e profanas. Ressalta a importância das festas na prática da conversão jesuítica e o caráter edificante e convencional do relato da festa, feito por um padre italiano, com base em um texto maior, escrito em português. Os desfiles com os carros alegóricos e vários personagens são descritos com riquezas de detalhes e interpretados como símbolos da vitória do bem contra o mal, com grande destaque para o papel da Companhia, que aparece estreitamente vinculada à expansão ultramarina também ali devidamente enaltecida. A festa que envolve os diferentes segmentos sociais da colônia apresenta-se, pois, "como o momento que marca o triunfo da missão apesar de todas as dificuldades".

A imagem de esterilidade da vinha é retomada na conclusão e remetida à ausência da palavra dos índios nas fontes jesuíticas, de forma que, segundo Charlotte, esta sua história do projeto missionário foi construída sobre o silêncio dos índios. Não obstante, este silêncio não deve ser visto, a meu ver, como total ausência dos índios no processo de construção do projeto missionário. Afinal, se a 
experiência missionária local dava as diretrizes para as resistências, as negociações e os acordos entre periferia e centro, ela era, sem dúvida, fortemente influenciada pela presença e pela atuação dos índios, com os quais os missionários interagiam. Por fim, se para os missionários a imagem da vinha exprimia as dificuldades da missão, para os historiadores ela permite, segundo a autora, refletir sobre estas dificuldades sem julgamentos de valor, utilizando as categorias de análise e a percepção dos próprios missionários.

Concluo ressaltando o imenso valor desta obra, cujas instigantes questões brilhantemente levantadas e discutidas reforçam a importância dos estudos interdisciplinares e globalizantes que complexificam as relações entre centro e periferia, abrindo novas perspectivas de análise para a história colonial, para a antropologia religiosa e para a história indígena. 